I. Crônicas

1. Crônicas da atualidade do Direito Internacional ......................................................16

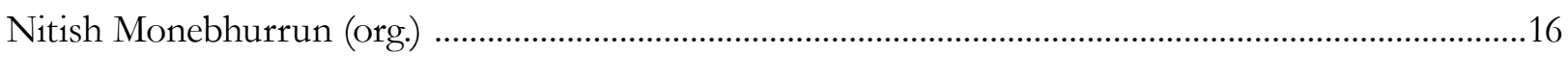

2.Decisões da Corte Internacional de Justiça e do Tribunal Internacional Sobre o Direito do Mar

Nitish Monebhurrun

José Eduardo Siqueira

3. Crônicas do direito internacional dos inVestimentos

Nitish Monebhurrun

\section{Os Vinte Anos dA OMC}

EXPORT CONTROLS AS INDUSTRIAL POLICY ON NATURAL RESOURCES: REGULATORY LIMITATIONS ON CHINA - RAW MATERIALS AND CHINA - RARE EARTHS CASES.

Gustavo Ferreira Ribeiro

O problema da espionagem econômica internacional: Seria a Organização Mundial do CoMÉRCIO O FORO ADEQUADO PARA SUA APRECIAÇÃO?

Humberto A.Vasconcelos Lima

Naiana Magrini Rodrigues Cunha

International Standards for Intellectual Property Rights Protection: a reflection on CLIMATE-FRIENDLY TECHNOLOGY TRANSFER.

Guihong Zhang

Jiani Jiang

Can Wang

Os vinte anos da OMC, suas conquistas e desafios: uma análise do Brasil e o Sistema de SoLUÇõES DE CONTROvÉRsias

Etiene M. Bosco Breviglieri

Luciano Meneguetti Pereira

A relação entre os tratados multilaterais ambientais e os acordos da OMC: é possível CONCILIAR O CONFLITO?

Fabio Costa Morosini,

Luisa Zuardi Niencheski 
Um desafio na Organização Mundial do Comércio: viabilidade de um acordo plurilateral

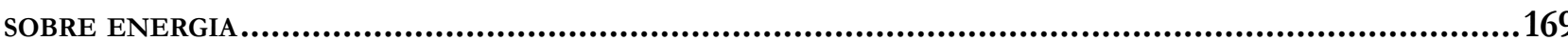

Matheus Linck Bassani

ContrataÇões PÚblicas No ÂMbito da OMC: A POLÍtica legislativa brasileira À LUZ do direito AO DESENVOLVIMENTO .192

André Jansen do Nascimento

Governança global e a Organização Mundial do Comércio: desafios impostos pelo novo MANDATO DE DESENVOLVIMENTO

Letícia de Souza Daibert

Ana Luísa Soares Peres

Vinte Anos de Crise para a África? Poder, Assimetrias e a Abordagem Liberal da OMC.....239 Igor Abdalla Medina de Souza

OS MECANISMOS DE INDUÇÃo AO CUMPRIMENTO NO ÂMBITO DA OMC .258

Fernando Lopes Ferraz Elias

A promoção de accountability na Organização Mundial do Comércio: uma análise hori-

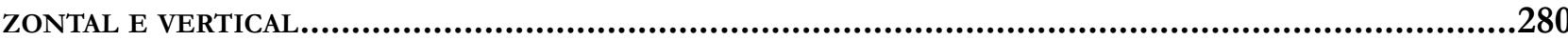

Celso Henrique Cadete de Figueiredo

LA OMC Y EL PROCESO DE GLOBALIZACION DE LA REGULACIÓN ALIMENTARIA .307

Maria Eugenia Marichal

O ACORDo GATS E SUA APLICAÇÃo AOS SERVIÇOS DO COMÉRCIO ELETRÔNICO

Gleisse Ribeiro Alves

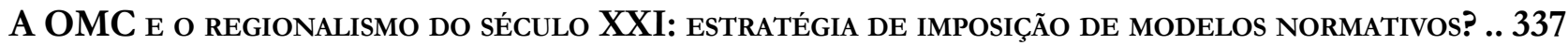

Camilla Capucio

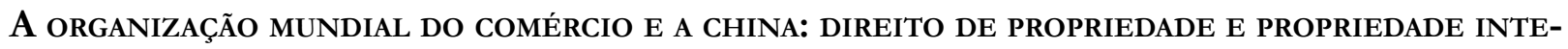
LECTUAL NO PAÍS

Dos CONTEnciosos NA OMC COM ENFOQUe EM RESTRIÇÕES Às EXPORTAÇõES DA CHINA .363 Marco Antônio Alcântara Nascimento 
Alice Rocha da Silva

\section{Outros Temas}

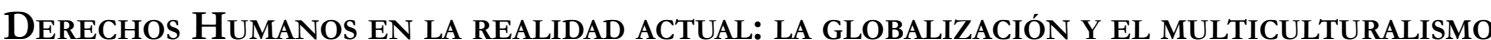

David Falcão

IMUNIDADE DE JURISDIÇÃo do EsTAdo E REPARAÇÃo CIVIL PELA PRÁtica de TORTURA: O CASO ZaHRA

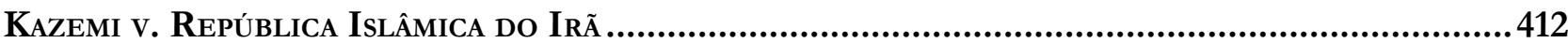

Patrícia Maria Lara Abreu

Rodrigo Otávio Bastos Silva Raposo

INTERREgIONAL ORgaNiZATIONS (IROS) IN EUROPE: NEW SUBJECTS OF CONTEMPORARY INTERNATIONAL LAW?

Davorin Lapas

A CONEXÃo ENTRE OS DIREITOS HUMANOS E A CORRUPÇÃo

Gabriela Alves Mendes Vieira

Marcelo Dias Varella

GRUPO DE SOCIEDADES: INSTRUMENTO JURÍDICO DE ORGANIZAÇÃO DA EMPRESA PLURISSOCIETÁRIA.....495

Daniel Amin Ferraz 


\title{
O problema da espionagem econômica internacional: seria a Organização Mundial do Comércio o foro adequado para sua apreciação?
}

\author{
International economic espionage: Is the World \\ Trade Organization the proper forum for addressing \\ the problem?
}

\author{
Humberto A.Vasconcelos Lima** \\ Naiana Magrini Rodrigues Cunha***
}

\section{Resumo}

Valendo-se dos eventos que revelaram o programa de espionagem econômica cibernética conduzida pela China sobre os Estados Unidos, este trabalho tem por objetivo analisar criticamente, sob uma ótica puramente normativa, uma das soluções sugeridas para dirimir o problema, qual seja, submeter a questão ao Órgão de Solução de Controvérsias da Organização Mundial do Comércio (OMC). Para tanto, neste estudo se analisa a relação que se estabelece entre atividades de espionagem econômica e propriedade intelectual, e posteriormente entre esta e o comércio internacional. Posteriormente, o mérito da questão é enfrentado, quando se verifica conclusivamente que o sistema de solução de controvérsias da OMC comporta analisar atos de espionagem econômica entre membros caso haja violação direta ao artigo 39 do acordo TRIPS convertida em uma distorção concreta ao comércio internacional. A contribuição do trabalho consiste na crítica e reconstrução de conclusões extraídas em estudos anteriores a respeito do mesmo tema.

Palavras-Chave: Organização Mundial do Comércio. Espionagem econômica. Segredo de empresa. Propriedade intelectual.

\section{Abstract}

Taking, as a referential, the events that revealed China's economic cyber espionage program conducted over the United States, this work aims to analyze critically and from a purely normative perspective, one of the suggested alternatives to solve the problem: submit the matter to the Dispute Settlement Body of the World Trade Organization (WTO). To undertake this task, this study analyzes the relationship established between economic espionage activities and intellectual property, and subsequently between intellectual property rights and international trade. Later, the central question is faced, and we have concluded that the dispute settlement system of the WTO have the power to analyze acts of economic espionage between WTO members provided that a direct violation of Article 39 of the TRIPS agreement be converted into a concrete distortion on international trade. The contribution of this work consists in a critique and reconstruction of the conclusions reached in previous studies about the same subject matter.

Keywords: World Trade Organization. Economic espionage. Trade secret. Intellectual property.

*** Graduanda em Direito pela UFMG e Bolsista do CNPq, naianamagrinir@ gmail.com.
* Recebido em 09.19.2014

**Doutorando em Direito Internacional pela UFMG e Mestre em Inovação e Propriedade Intelectual pela UFMG, humbertoavlima@gmail.com. 


\section{Introdução}

Em outubro de 2011 o Office of The National Counterintelligence Executive encaminhou ao Congresso estadunidense relatório intitulado "Foreign Spies Stealing US Economic Secrets in Cyberspace". O documento alertava que tecnologias e informações econômicas sensíveis dos Estados Unidos eram alvo constante de espionagem estrangeira, principalmente conduzida pela China caracterizada no relatório como "Persistente Coletora" - e pela Rússia.

Reconhecendo as ameaças, o executivo estadunidense publica, em fevereiro do ano de 2013, o estudo "Administration Strategy on Mitigating the Theft of U.S. Trade Secrets" (Estratégia da Administração na Mitigação do Roubo de Segredos Comerciais dos Estados Unidos). ${ }^{2}$ Uma extensa lista de casos criminais que envolveram obtenção ilícita de segredo de empresa por chineses em companhias privadas (por exemplo: Dupont, General Motors, Ford, Cargill) e setores do governo dos Estados Unidos é anexada ao documento.

Evidências mais concretas permitiram associar a origem de atos de ataque cibernético ao território chinês. Uma companhia privada de segurança cibernética norte-americana, Mandiant, por conseguir rastrear a fonte de atividades de ciberespionagem com alvo nos Estados Unidos até instalações militares do Exército de Libertação Popular em Xangai (especificamente na “unidade 61398”- 61398部队), apresentou em relatório dados consistentes que permitiram concluir que o governo chinês conduz programas de ciberespionagem comercial. ${ }^{4}$ Setores estratégicos da economia norte-

1 OFFICE OF THE NATIONAL
COUNTERINTELLIGENCE EXECUTIVE (ONCIX). Foreign spies stealing US economic secrets in cyberspace: report to Congress on foreign economic collection and industrial espionage, out. 2011. Available at: <http://www.ncix.gov/publications/reports/fecie_ all/Foreign_Economic_Collection_2011.pdf $>$ Last access on: 09 aug. 2014. p. 1-5.

2 EXECUTIVE OFFICE OF THE PRESIDENT OF THE UNITED STATES. Administration strategy on mitigating the theft of U.S. trade secrets, feb. 2013. Available at: <http://www.whitehouse.gov/ sites/default/files/omb/IPEC/admin_strategy_on_mitigating_ the_theft_of_u.s._trade_secrets.pdf> Last access on: 09 aug. 2014.

3 EXECUTIVE OFFICE OF THE PRESIDENT OF THE UNITED STATES. Administration strategy on mitigating the theft of U.S. trade secrets, feb. 2013. Available at: <http://www.whitehouse.gov/ sites/default/files/omb/IPEC/admin_strategy_on_mitigating_ the_theft_of_u.s._trade_secrets.pdf> Last access on: 09 aug. 2014. Cf. o anexo do documento: "Summary of Department of Justice Economic Espionage and Trade Secret Criminal Cases".

4 MANDIANT. ATP1: exposing one of China's cyber espionage Units, 2013. Available at: <http://intelreport.mandiant. americana foram, segundo o relatório, alvos da espionagem chinesa, tais como empresas de jornalismo (The Wall Street Journal, The New York Times, Bloomberg), empresas de tecnologia (Google, Adobe, Yahoo), e a Coca-Cola. O então Diretor da National Security Agency (NSA), o General Keith Alexander, afirmou em 2012 que estes eventos representam a maior transferência de riqueza da história 5 . É importante considerar ainda os riscos que esse tipo de atividade implica para a segurança estadunidense, quando se sabe que empresas terceirizadas do ramo de defesa, como a Lockheed Martin, também foram alvo desses ataques.

Diante da massiva quantidade de evidências - em alguns casos provas diretas - da espionagem estatal chinesa, a reação do governo Obama para lidar com o problema evoluiu de medidas diplomáticas ${ }^{7}$, para o campo jurídico, quando cinco oficiais do exército chinês foram acusados perante o judiciário dos Estados Unidos por atos de ciberespionagem - a primeira vez que agentes de Estado estrangeiros foram acusados perante cortes do país por esse tipo de conduta, segundo o procurador-geral Eric Holder.

com/Mandiant_APT1_Report.pdf $>$ Last access on: 09 ago. 2014.

5 O General esclareceu que companhias norte-americanas perdem cerca de 250 bilhões de dólares por ano por "subtração" de propriedade intelectual, além de 114 bilhões perdidos anualmente com crimes cibernéticos. Cf. ROGIN, Josh. NSA chief: cybercrime constitutes the greatest transfer of wealth in history. Foreign Policy, 9 jul. 2012. Available at: <http://thecable.foreignpolicy.com/ posts/2012/07/09/nsa_chief_cybercrime_constitutes_the_ greatest_transfer_of_wealth_in_history> Last access on: 16 apr. 2014.

6 MANDIANT. ATP1: exposing one of China's cyber espionage Units, 2013. Available at: <http://intelreport.mandiant. com/Mandiant_APT1_Report.pdf> Last access on: 09 ago. 2014.

7 Negociações diplomáticas sobre a questão da ciberespionagem fracassaram em diálogos EUA-China que aconteceram em meados do ano de 2013. Cf. ROBERTS, Dan; GOLDENBERG, Suzanne. US-China summit ends with accord on all but cyber-espionage. The Guardian, 10 jun. 2013. Available at: <http://www.theguardian.com/ world/2013/jun/09/us-china-summit-barack-obama-xi-jinping > Last access on: 10 ago. 2014.

8 Os cinco oficiais chineses, Wang Dong, Sun Kailiang, Wen Xinyu, Huang Zhenyu, e Gu Chunhui, foram indiciados por um Grand Jury do Distrito Oeste da Pensilvânia com acusações associadas à ciberespionagem econômica, direcionadas contra as empresas Westinghouse, SolarWorld, U.S. Steel, ATI, USW e Alcoa Inc. Cf. THE UNITED STATES DEPARTMENT OF JUSTICE. U.S. charges five chinese military hackers for cyber espionage against U.S. corporations and a labor organization for commercial advantage, 19 mai 2014. Available $\quad$ at: <http://www.justice.gov/opa/pr/2014/May/14ag-528.html> Last access on: 10 aug. 2014. 
É fácil perceber que tais acusações guardam pretensões estritamente políticas ${ }^{9}$ pois uma condenação criminal dependeria da cooperação do governo chinês na extradição dos indiciados, o que não se espera que ocorra tendo em vista que suas autoridades negam enfaticamente ter patrocinado atividades de espionagem. Portanto, não se pretende que sejam solução efetiva para o problema. Por isso, paralelamente, o governo dos Estados Unidos considera outras opções. Vozes no congresso norte-americano ${ }^{10}$, na sociedade civil $^{11}$ e na academia $^{12}$ sugeriram que a adoção de uma medida mais grave consistiria em apresentar a questão da espionagem econômica chinesa ao Órgão de Solução de Controvérsias da Organização Mundial do Comércio (OMC).

Esse estudo tem por objetivo analisar a viabilidade jurídica dessa proposta, que será utilizada apenas como uma referência para a problematização; em outros termos: pretende verificar se as regras que regulamentam a solução de controvérsias, no âmbito da OMC, comportam a análise de demandas de tal natureza, não apenas no que se refere aos eventos de espionagem China-EUA. Não se pretende avaliar neste estudo, por outro lado, a viabilidade política de se apresentar consultas na OMC sobre matéria ligada à espionagem econômica, problema que conduziria a uma abordagem de outra natureza.

\section{Espionagem econômica, propriedade intelectual e comércio internacional}

Para que se possa responder à indagação "A OMC pode analisar casos de espionagem econômica entre Estados?", é preciso compreender o próprio sentido de se estabelecer a pergunta, ou seja, como há uma

9 Uma interessante análise dos reais objetivos das acusações pode ser lida em: CHABROW, Eric. The real aim of the U.S. indictment of chinese. Bank Info Security, 20 mai 2014. Available: $<$ http://www.bankinfosecurity.com/real-aim-us-indictmentchinese-a-6854/op-1> Last access on: 10 aug. 2014.

10 Em 22 de maio de 2014, o Senador Charles E. Schumer enviou uma carta ao U.S. Trade Representative, Michael Froman, solicitando que a questão da epsionagem econômica chinesa fosse apresentada à OMC. A carta pode ser lida em: < http:/ / www.schumer.senate.gov/ Newsroom/record.cfm?id=351779> Acesso em: 11 ago. 2014.

11 Cf. LEWIS, James A. Conflict and negotiation in cyberspace. Washington: Center for Strategic and International Studies, 2013. p. 49.

12 SKINNER, Christina Parajon. An international law response to economic cyber espionage. Connecticut Law Review, v. 46, n. 4, p. 1198-1199, 2014. associação teoricamente possível entre matéria comercial e atos de espionagem.

\subsection{Espionagem econômica como tema afeto à propriedade intelectual}

Uma primeira definição que se mostra relevante nessa tarefa é o conceito de espionagem com finalidades econômicas ou simplesmente "espionagem econômica". O conceito de espionagem não encontra definição técnica no Direito Internacional, mas pode ser ela compreendida como uma modalidade da atividade de inteligência de Estado. Por meio de agências especializadas, o Estado busca reunir informação relevante na maior quantidade e melhor qualidade possível, para que assim possa aprimorar seu processo decisório. ${ }^{13}$

Ocorre que os Estados não limitam suas atividades de inteligência apenas à utilização de mecanismos públicos e transparentes, exatamente por existirem informações que não podem ser obtidas por esse meio. Realmente, um serviço de inteligência que se limitasse à obtenção de informação pública se mostraria pouco relevante. Por essa razão, paralelamente, os Estados conduzem operações secretas de coleta de informações classificadas ou por outra forma ocultadas, no sentido de que são realizadas sem o conhecimento do público e, principalmente, do detentor da informação que a tem sob segredo. Ao fazê-lo, o Estado pratica espionagem, e nesse sentido é que pode-se dizer que a espionagem se apresenta como uma modalidade da inteligência, mais precisamente, uma forma clandestina de inteligência, qualificada pelo binômio (operação secreta de coleta + informação secreta a ser coletada).

O aparato de inteligência dos Estados pode ser voltado, então, sob a forma de espionagem, à obtenção de informações secretas de empresas ou órgãos públicos de outros Estados. Se esta informação for mantida sob segredo por razões econômicas estaremos diante de um segredo de empresa ${ }^{14}$, uma espécie de propriedade intelectual.

13 Sobre o papel das atividades de inteligência nas relações internacionais conferir: MCDOUGAL, Myres S.; LASSWELL, Harold D.; REISMAN, W. Michael. The intelligence function and world public order. Temple Law Quarterly, v. 46, n.3, p. 365-448, 1973.

14 Neste trabalho pressupõe-se que as expressões "segredo de empresa", "segredo de indústria", "segredo de comércio", "segredo de negócio", "segredo de fábrica", "trade secret", "informações confidenciais" (desde que com valor comercial), são sinônimas 
Explica-se: o detentor desse tipo de informação tem um interesse legítimo e juridicamente protegido em mantê-la sob segredo, pois, por possuir ela valor econômico, sua confidencialidade lhe garante vantagens concorrenciais. Pense-se, por exemplo, em uma empresa que desenvolve um novo combustível automotivo. Ela tem a opção, de um lado, de solicitar uma patente do produto - caso em que a tecnologia será publicada - e assim se beneficiar de um período limitado de exclusividade em sua exploração econômica ou mesmo licenciar, neste mesmo prazo, a tecnologia para concorrentes, como fonte de royalties. De outro lado, pode optar por manter a fórmula do combustível sob segredo de empresa indefinidamente e com isso auferir uma vantagem competitiva sobre outras empresas do mesmo setor enquanto for capaz de sustentar a confidencialidade, ou enquanto a mesma tecnologia não for desenvolvida por outros através de meios lícitos.

Sob esse espírito, no que diz respeito ao Direito Interno (por exemplo o do Brasil e o dos Estados Unidos), atos de espionagem econômica são proscritos, pois suas normas de proteção à concorrência desleal tutelam o segredo de empresa contra obtenções fraudulentas. Esse conjunto de normas geralmente carcaterizará como crime a exploração de informações confidenciais obtidas de forma clandestina. ${ }^{15}$

Todavia, quando se analisa a espionagem econômica a nível internacional, surgem dúvidas a respeito do alcance da proteção a segredos de empresas e sobre a maneira mais adequada de dirimir conflitos associados a tal tipo de atividade. Questiona-se: há uma proibição

e significam, conforme definido no Economic Espionage Act (EEA) dos Estados Unidos, de 1996, “[...] todas as formas e tipos de informação financeira, comercial, técnica, econômica ou de engenharia, incluindo-se padrões, planos, compilações, dispositivos de programa, fórmulas, desenhos, protótipos, métodos, técnicas, processos, procedimentos, programas ou códigos, tangíveis ou intangíveis, tanto estocado, quanto compilado ou memorizado, fisicamente, eletronicamente, graficamente, em fotografia, ou em escrita [...]". UNITED STATES OF AMERICA. Economic espionage act. Washington, 2 october 1996.

15 A Lei 9.279/96, a Lei Brasileira de Propriedade Industrial, tipifica como crime de concorrência desleal, em seu art. 195, incisos XI, XII, XIII e XIV, atos de divulgação, exploração ou utilização de segredos de empresa. BRASIL. Lei 9.279, de 14 de maio de 1996. Regula direitos e obrigações relativos à propriedade industrial. Disponível em: <http://www.planalto.gov.br/ccivil_03/leis/19279. htm>. Acesso em: 9 ago. 2014. no Direito Internacional de que Estados espionem uns aos outros com finalidades econômicas e, se sim, de onde vem essa proibição? Como resolver, juridicamente, casos de espionagem econômica entre Estados (como o caso China-EUA)?

Sabendo-se que espionagem econômica é tema relacionado à propriedade intelectual, possíveis respostas às perguntas acima propostas devem começar a ser construídas considerando-se as regras que disciplinam a propriedade intelectual a nível internacional. Essas regras foram ajustadas no acordo TRIPS (Trade-Related Aspects of Intellectual Property Rights) que é um dos instrumentos anexos ao GATT (General Agreement on Tariffs and Trade) de 1994, portanto, um sistema normativo da propriedade intelectual em um contexto maior de comércio internacional.

Logo, uma possível solução para o problema da espionagem econômica poderia residir na relação entre sistema internacional da propriedade intelectual e sistema do comércio internacional, que se consubstancia no acordo TRIPS. Entender o vínculo que existe entre esses dois domínios é essencial para evoluir na análise do problema.

\subsection{O vínculo entre propriedade intelectual $\mathrm{e}$ comércio internacional ${ }^{10}$}

Há uma relação material entre propriedade intelectual e comércio internacional que se estabelece quando a ausência de proteção à propriedade intelectual em determinado país representa uma barreira ao comércio de produtos originados de um segundo país em que esses direitos são protegidos. ${ }^{17}$ Isso ocorre porque produtos protegidos por propriedade intelectual naturalmente refletirão um preço mais elevado que produtos análogos que desempenham a mesma função mas não concentram os gastos com

16 Para uma análise detalhada do vínculo entre propriedade intelectual e comércio internacional conferir: LIMA, Humberto Alves de Vasconcelos. A construção do vínculo entre propriedade intelectual e comércio internacional e seus reflexos no Brasil. Revista Eletrônica Direito e Politica, v. 9, n. 2, 2014. Disponível em: < http:// www6.univali.br/seer/index.php/rdp/article/view/6033>. Acesso em: 9 ago. 2014.

17 MATSUSHITA, Mitsuo; SCHOENBAUM, Thomas J.; MAVROIDIS, Petros C. The World Trade Organization: law, practice and police. Oxford: Oxford University Press, 2006. p. 397. 
pesquisa e desenvolvimento, com criação de marca e com o patenteamento em relação ao que aqueles demandaram. Pense-se, por exemplo, em uma empresa canadense que desenvolva um medicamento inovador para o tratamento da hipertensão. $O$ preço desse medicamento irá refletir todos os gastos expendidos com a pesquisa e o desenvolvimento do composto, com a criação e registro da marca e com o patenteamento do produto (custos que aumentam em proporção direta ao número de países em que se pretende ver protegido o produto por propriedade intelectual). Agora suponhase que a empresa canadense pretenda vender seu produto em um país em que não são admitidas patentes sobre medicamentos. Ora, a empresa canadense não conseguirá competir com outras empresas que poderão produzir e comercializar o mesmo composto a preços inferiores, pois não precisarão amortizar os mesmos gastos que a primeira suportou.

Por perceberem essa relação, os países desenvolvidos - na posição de grandes exportadores de tecnologia e de produtos inovadores - buscaram inserir normas de proteção à propriedade intelectual no compromisso de liberação do comércio internacional, ao aprovarem o GATT de 1994 na Rodada de Negociações do Uruguai. Disto resultou a formalização do acordo TRIPS vínculo formal inédito entre propriedade intelectual e comércio internacional - ajustado no desejo de seus signatários de reduzir distorções e obstáculos ao comércio internacional, promover uma proteção eficaz e adequada dos direitos de propriedade intelectual e assegurar que as medidas e procedimentos destinados a fazê-los respeitar não se tornem, por sua vez, obstáculos ao comércio legítimo. ${ }^{18}$

$\mathrm{O}$ acordo TRIPS estabelece parâmetros mínimos de proteção à propriedade intelectual nas suas diversas modalidades (invenções, direitos de autor, marcas, indicações geográficas, desenho industrial, topografias de circuitos integrados, informações confidenciais e concorrência desleal), que devem ser aceitos pelos seus signatários (todos membros da OMC) e implementados por eles internamente em seus territórios. No que tange às informações confidenciais (ou segredos de empresa), o acordo TRIPS, em seu artigo 39, dispõe que detentores de informações secretas e de valor comercial terão a

18 ORGANIZAÇÃO MUNDIAL DO COMÉRCIO. Acordo sobre aspectos dos direitos de propriedade intelectual relacionados ao comércio, 1994. Disponível em: <http://www.fd.uc.pt/CI/CEE/OI/ OMC.GATT/OMC-Anexo_1C.htm>. Acesso em: 9 ago. 2014. Preâmbulo. possibilidade de evitar que informação legalmente sob seu controle seja divulgada, adquirida ou usada por terceiros, sem seu consentimento, de maneira contrária a práticas comerciais honestas. ${ }^{19}$

Sobre a invocação de tal regra, sustentam-se os principais argumentos que postulam a adequabilidade da submissão de litígios envolvendo espionagem econômica entre Estados ao Órgão de Solução de Controvérsias da OMC.

Estando demonstrado então que atividades de espionagem econômica dizem respeito à propriedade intelectual e que há um vínculo entre essa matéria e o comércio internacional, resta então enfrentar o problema central proposto no trabalho, que é o de verificar se o sistema de solução de controvérsias da OMC comporta a análise daquelas atividades.

\section{Espionagem econômica diante das normas do acordo TRIPS e do sistema de solução de controvérsias da OMC}

As normas e procedimentos sobre solução de controvérsias da OMC se aplicam a todos os acordos que compõem o GATT/1994 e ao acordo constitutivo da Organização ("Tratado de Marráquexe ${ }^{20 ")}$ ), como

19 Texto integral do artigo 39 do acordo TRIPS: "1. Ao assegurar proteção efetiva contra competição desleal, como disposto no Artigo 10bis da Convenção de Paris (1967), os Membros protegerão informação confidencial de acordo com o parágrafo 2 abaixo, e informação submetida a Governos ou a Agências Governamentais, de acordo com o parágrafo 3 abaixo. 2. Pessoas físicas e jurídicas terão a possibilidade de evitar que informação legalmente sob seu controle seja divulgada, adquirida ou usada por terceiros, sem seu consentimento, de maneira contrária a práticas comerciais honestas, desde que tal informação: (a) seja secreta, no sentido de que não seja conhecida em geral nem facilmente acessível a pessoas de círculos que normalmente lidam com o tipo de informação em questão, seja como um todo, seja na configuração e montagem específicas de seus componentes; (b) tenha valor comercial por ser secreta; e (c) tenha sido objeto de precauções razoáveis, nas circunstâncias, pela pessoa legalmente em controle da informação, para mantê-la secreta. 3. Os Membros que exijam a apresentação de resultados de testes ou outros dados não divulgados, cuja elaboração envolva esforço considerável, como condição para aprovar a comercialização de produtos farmacêuticos ou de produtos agrícolas químicos que utilizem novas entidades químicas, protegerão esses dados contra seu uso comercial desleal. Ademais, os Membros adotarão providências para impedir que esses dados sejam divulgados, exceto quando necessário para proteger o público, ou quando tenham sido adotadas medidas para assegurar que os dados sejam protegidos contra o uso comercial desleal." ORGANIZAÇÃO MUNDIAL DO COMÉRCIO. Acordo sobre aspectos dos direitos de propriedade intelectual relacionados ao comércio, 1994. Disponível em: < http://www.fd.uc.pt/CI/CEE/OI/OMC. GATT/OMC-Anexo_1C.htm>. Acesso em: 9 ago. 2014.

20 Optou-se pela grafia "Marráquexe" que é a recomendada para o português brasileiro. A palavra sem o acento agudo (Marraquexe) 
definido em seu Anexo 2 (Entendimento Relativo às Normas e Procedimentos sobre Solução de Controvérsias), Artigo 1 e Apêndice 1. Abrangem, portanto, o acordo TRIPS, de sorte que o órgão de solução de controvérsias é competente para apreciar litígios envolvendo propriedade intelectual. Com efeito, como observa John H. Jackson, "virtually every aspect of economic regulation and policy is touched upon at least potentially, if not actually [...]"21

Diante disso, é possível formular a seguinte premissa lógica: se um ato de espionagem econômica internacional viola uma ou mais normas do GATT, incluindo-se o acordo TRIPS, poderá ele ser objeto do sistema de solução de controvérsias da OMC. Note-se que isso não significa afirmar que somente poderão ser objetos do sistema de solução de controvérsias atos que violem diretamente normas do GATT. Com efeito, é possível que o órgão, atendidas algumas condições, aprecie condutas que não afetem diretamente obrigações do GATT, hipótese que será melhor analisada posteriormente.

\subsection{Atos de espionagem econômica violam obrigações assumidas no acordo TRIPS?}

Uma constatação que deve ser colocada antes da análise dessa questão é a de que não há norma no Direito Internacional positivo que proíba a prática da espionagem em tempos de paz $^{22}$, de forma genérica, entre os Estados. ${ }^{23} \mathrm{~A}$ ausência de qualquer tratado

é a utilizada no português oficial da União Europeia, enquanto as formas "Marrakech" e "Marraquesh" designam, respectivamente, a expressão no francês e no inglês.

21 JACKSON, John H. Sovereignty, the WTO and changing fundamentals of international law. Cambridge: Cambridge University Press, 2006. p. 135.

22 No que diz respeito à espionagem no contexto de um conflito armado internacional, a situação do espião está disciplinada no artigo 46 do Protocolo I Adicional às Convenções de Genebra de 1949 relativo à Proteção das Vítimas dos Conflitos Armados Internacionais. Afirma-se em seu item 1: “[...] o membro das forças armadas de uma Parte no conflito que cair em poder de uma Parte adversa enquanto se dedica a atividades de espionagem não terá direito ao estatuto de prisioneiro de guerra e poderá ser tratado como espião".

23 Cf. DEMAREST, Geoffrey B. Espionage in international law. Denver Journal of International Law and Policy, Glenn; YOO, John. Counterintuitive: intelligence operations and international law. Michigan Journal of International Law, v. 28, p. 625-638, 20062007; STONE, Julius. Legal problems of espionage in conditions of modern conflict. In: STANGER, Roland J. (Org.) Essays on espionage and international law. Athens: Ohio University Press, 1962. NORTH ATALNTIC TREATY ORGANIZATION. Tallin manual que proscreva a atividade é explicada em razão de que possuem os Estados interesses recíprocos em obter informações confidenciais uns dos outros. Ainda que cada qual possa fazê-lo com maior ou menor eficiência, a tolerância da prática contribuiria, em termos gerais e entre outras formas, para o monitoramento recíproco durante a execução de obrigações convencionais, especialmente em acordos de segurança global, exemplificativamente. ${ }^{24}$

É importante considerar ainda que o fato de os Estados se engajarem permanentemente em atividades de espionagem, não implica a conclusão de ter disso se derivado a formação de costume internacional que autorize a prática. Isso porque a perfeita configuração dessa fonte exige, além da verificação do elemento objetivo de generalidade da prática, o elemento subjetivo consubstanciado no reconhecimento do Estado de que a adoção de tal "postura" é obrigatória (opinio juris sive necessitatis). Comportamentos adotados pelos Estados, por qualquer outra razão que não seja a crença de se estar cumprindo com algo obrigatório perante o Direito Internacional, não geram costume internacional. ${ }^{25}$ No caso da espionagem, a evidência e a prática são adotadas por liberalidade e tolerância.

Se a espionagem, em sua forma genérica, mostrase como algo não proscrito pelo Direito Internacional, extrair automaticamente as mesmas conclusões para toda espécie de espionagem seria tarefa apressada e poderia conduzir a equívocos. Isso porque, no que se refere à espionagem econômica, como já afirmado anteriormente, há um dispositivo legal que possivelmente enquadraria a atividade, isso é, o art. 39 do acordo TRIPS (transcrito na seção 2.2$)^{26}$ que,

on the international law applicable to cyber warfare. Cambridge: Cambridge University Press, 2013. p 36; OPPENHEIM, Lassa. International law. 3. ed. London: Longmans, 1920. \455.

24 BAKER, Christopher D. Tolerance of international espionage: a functional approach. American University International Law Review, v. 19, n. 5, p. 1091-1113, 2003.

25 Como esclarece Malcolm Shaw, "The issue therefore is how to distinguish behaviour undertaken because of a law from behaviour undertaken because of a whole series of other reasons ranging from goodwill to pique, and from ideological support to political bribery. And if customary law is restricted to the overt acts of states, one cannot solve this problem". SHAW, Malcolm N. International law. 6. ed. Cambridge: Cambridge University Press, 2008. p. 75.

26 A única oportunidade em que o artigo 39 do TRIPS figurou em uma controvérsia apreciada na OMC foi na disputa DS 196, na qual os Estados Unidos questionavam dispositivos da legislação argentina que não conferiam proteção adequada às informações confidenciais relativas a testes prévios obrigatórios para comercialização de produtos farmacêuticos e químicos. Aqui 
ao impor uma obrigação aos membros de protegerem informação confidencial, em tese proibiria a prática de obtenção clandestina de segredo de empresa entre Estados.

Ocorre que as normas substantivas do acordo TRIPS foram construídas sob a ideia subjacente de que os parâmetros mínimos de proteção à propriedade intelectualaos quais devem os membros da OMCadequar sua legislação interna impõem-se territorialmente. Em regra, não destinam obrigações internacionais a serem adimplidas extraterritorialmente, como defende David Fidler:

One reason why WTO members have not used the WTO is the difficulty of formulating claims that economic espionage violates WTO agreements. WTO rules create obligations for WTO members to fulfill within their territories and do not generally impose duties that apply outside those limits. WTO members that covertly obtain intellectual property of nationals of other WTO members operating in their territories could violate WTO obligations to protect such property. However, the economic espionage of greatest concern-and especially acts of remotely conducted economic cyber espionage-involves governments obtaining information from private-sector companies located outside their territories. ${ }^{27}$

Reforçando a mesma ideia em outro texto, afirma o autor:

Nothing in the WTO generally or TRIPS specifically mandates that China (or any other WTO member) protect commercially valuable information found in the territories of other countries. TRIPS does not require WTO members to prohibit their nationals or companies from engaging in corporate espionage inside foreign nations, nor does TRIPS regulate governmentled economic espionage within other countries. Thus, the US cannot claim that China is violating TRIPS

se aplica o item 3 do artigo 39 do TRIPS, não havendo, no caso, qualquer ocorrência concreta de violação à confidencialidade de segredo de empresa. Cf. WORLD TRADE ORGANIZATION. Argentina: certain measures on the protection of patents and test data, 2002. Available: <http://www.wto.org/english/tratop_e/ dispu_e/cases_e/ds196_e.htm> Last access on: 29 aug. 2014.

27 FIDLER, David. P. Economic cyber espionage and international law: controversies involving government acquisition of trade secrets through cyber technologies. American Society of International Law Insights, v. 17, n. 10, 20 mar. 2013. Available at: <http://www.asil.org/insights/volume/17/issue/10/economiccyber-espionage-and-international-law-controversies-involving $>$ Last access on: 25 aug. 2014. with respect to Chinese economic cyber espionage the US fears is most damaging to US economic and commercial interests. Or, put another way, China has not made commitments under the WTO regarding espionage it conducts outside its territory, meaning the US cannot claim breach of legal obligations that justifies countermeasures involving trade restrictions against China. ${ }^{28}$

Insurgindo-se contra esta ideia - a de que as obrigações do acordo TRIPS não exigem de um signatário respeito à propriedade intelectual que se encontra extraterritório - Christina Parajon Skinner sugere uma interpretação que atenda aos fins do acordo e favoreça sua operabilidade e eficácia, como se pode extrair das seguintes considerações:

If a member state's actions taken from within its territory infringe on another member state's intellectual property rights, should not the WTO rules apply? That the harm is done in cyber space seems a poor reason to limit application of the TRIPS Agreement, which was, in any event, negotiated before the rise of cyber threats to trade and intellectual property rights. After all, the general goals of the TRIPS Agreement, found in its preamble, are to "reduce distortions and impediments to international trade ... [and] promote effective and adequate protection of intellectual property rights." In short, to remain relevant, the WTO Agreements must consider the possibility of cyber violations. ${ }^{29}$

A princípio, poder-se-ia acreditar que a dificuldade que se apresenta é de natureza hermenêutica, isto é, as disposições de um tratado devem ser interpretadas em um sentido conjuntural, prezando-se pela coerência sistêmica do acordo ou deve-se buscar uma interpretação que favoreça sua eficácia? No caso em exame: deve ser o art. 39 do acordo TRIPS interpretado segundo o contexto do tratado, cujas cláusulas estabelecem, eminentemente, obrigações territoriais ou deve-se optar pela interpretação que resulte na aplicação do dispositivo, para que "continue relevante", em atenção à sua finalidade?

28 FIDLER, David. P. Why the WTO is not an appropriate venue for addressing economic cyber espionage. Arms Control Law, $11 \mathrm{feb}$. 2013. Available at: <http://armscontrollaw.com/2013/02/11/whythe-wto-is-not-an-appropriate-venue-for-addressing-economiccyber-espionage/> Last access on: 30 aug. 2014.

29 SKINNER, Christina Parajon. An international law response to economic cyber espionage. Connecticut Law Review, v. 46, n. 4, p. 1198-1199, 2014. p. 1197. 
Todavia, esta seria uma forma precipitada de se formular o problema. Com efeito, é preciso analisar se, realmente, a posição exposta por David Fidler segundo a qual as regras ajustadas no acordo TRIPS impõem obrigações substantivas eminentemente territoriais, de sorte que uma interpretação contextual de seu art. 39 desaconselharia sua aplicação a atos conduzidos extraterritorialmente - é uma conclusão válida.

Em verdade, a perplexidade diante da questão se deve, em grande parte, ao fato de os atos de espionagem econômica serem conduzidos remotamente, por meio do ciberespaço - o que permite que oficiais do exército chinês posicionados na China obtenham segredos de empresa alocados em servidores no território estadunidense. Nesse quadro, um conceito de natureza física como o de territorialidade não se adequa com exatidão aos problemas relacionados à espionagem cibernética $^{30}$; na verdade compromete, inclusive, sua adequada compreensão. Com efeito, o acordo TRIPS foi elaborado em um momento em que não era possível a condução remota de espionagem na mesma dimensão em que o é atualmente, de sorte que, hoje, interpretar da sua natureza a característica da territorialidade das obrigações poderia conduzir a verdadeiros absurdos. Tome-se, por exemplo, o princípio do tratamento nacional (art. 3, item 1, acordo TRIPS) que determina, como regra, que "Cada Membro concederá aos nacionais dos demais Membros tratamento não menos favorável que o outorgado a seus próprios nacionais com relação à proteção da propriedade intelectual". Interpretando o dispositivo conforme uma acepção territorial das obrigações do acordo TRIPS - como sugere David Fidler - deveríamos concluir, por exemplo, que a China estaria, pelo princípio do tratamento nacional, obrigada a respeitar e tutelar o segredo de empresa (que pode consistir, e.g., tanto em técnicas industriais quanto em informações de mercado consumidor) mantido por fábricas da Ford em território chinês, mas não o estaria igualmente obrigada em relação às informações mantidas em servidores posicionados em unidades da empresa nos Estados Unidos, podendo obtê-los via espionagem cibernética. Trata-se de um resultado inadmissível pois implicaria em discriminação de proteção fundada simplesmente

30 Sobre as peculiaridades da espionagem conduzida no ciberespaço, conferir: WILLIAMS, Robert D. (Spy) game change: cyber networks, intelligence collection, and covert action. The George Washington Law Review, v. 79, n. 4, p. 1162-1200, 2011. p. 1183. na posição física e geográfica do segredo, e poderia consistir, inclusive, em uma medida protecionista para a indústria local. Portanto, certamente não se pode afirmar que as normas do acordo TRIPS não exigem respeito à propriedade intelectual que esteja fora dos limites territoriais de um Estado signatário.

Poresse motivo, assiste razão à objeção formulada por Christina Skinner, afirmando que o acordo TRIPS deve ser aplicado às atividades de espionagem cibernética. Todavia, a extensão da aplicabilidade do art. 39 deve ser balizada exatamente por uma interpretação teleológica do acordo. Como demonstrado anteriormente, a própria existência do acordo TRIPS se justifica e está sujeita ao contexto maior do comércio internacional, pois tem como principal norteador o objetivo de "reduzir distorções e obstáculos ao comércio internacional". Não se pode nunca perder de vista a natureza e a razão de ser desse vínculo. Em atenção a tal orientação, uma interpretação teleológica do art. 39 do acordo TRIPS evidencia que o dispositivo somente deve ser aplicado a situações em que a informação confidencial está associada diretamente ao comércio internacional.

Logo, atividades de espionagem econômica cibernética apenas irão violar o art. 39 do Acordo TRIPS, e assim poder ser objeto do procedimento de solução de controvérsias da OMC, se conduzirem a distorções concretas no comércio internacional, sendo que a mera obtenção clandestina da informação não seria suficiente para configurar uma infração à regra. Não está se afirmando com isso, frise-se, que a mera obtenção de segredo de empresa por espionagem cibernética não seja ilícita (tal análise não é objeto do presente estudo); apenas que, caso não venham a se converter em violação a regras e princípios do comércio internacional não poderão ser apreciadas na OMC, o que não impede que sejam dirimidas em outros foros internacionais.

\subsection{0 órgão de solução de controvérsias da OMC poderia apreciar atividades de espionagem econômica como uma violação a costume internacional?}

Outro argumento construído por Christina Skinner é o de que atividades de espionagem econômica internacional violam o costume internacional de não intervenção, em razão da obrigação de respeito à "soberania econômica" dos Estados. Sem definir o conteúdo do alegado princípio de "soberania econômica", mas, propondo seu argumento com base 
nele, conclui posteriormente a autora que poderia o Órgão de Solução de Controvérsias da OMC apreciar atividades de espionagem econômica internacional. ${ }^{3}$

Não há dúvidas de que o Direito do Comércio Internacional é parte do Direito Internacional e, portanto, reconhece as mesmas fontes de direitos e obrigações, notadamente os tratados, o costume internacional e os princípios gerais de direito para mencionar apenas fontes arroladas no art. 38 do Estatuto da Corte Internacional de Justiça. Foram diversas as oportunidades em que o Órgão de Solução de Controvérsias da OMC buscou suporte em elementos do Direito Internacional para fundamentar suas decisões. No caso United States - Gasoline, em que Brasil e Venezuela questionaram determinadas regras ambientais da legislação norte-americana a respeito do comércio de gasolina, o Órgão de Apelação reconheceu que princípios costumeiros influenciavam a interpretação de tratados, fazendo constantes menções às regras de interpretação presentes na Convenção de Viena sobre o Direito dos Tratados entre Estados (1969) como formalização da prática costumeira. ${ }^{32}$ Outros casos expressam outros pontos da relação "Comércio Internacional-Direito Internacional", como por exemplo: Japan - Alcoholic Beverages ${ }^{33}$; Korea - Government Procurement e United States - EC Hormones, neste último havendo invocação do princípio geral da boa-fé. ${ }^{34}$

31 Afirma a autora: "Customary international law also supports an expanded notion of sovereignty, which includes a concept of economic sovereignty that protects private sector actors that contribute to the nation's economic security [...] The economic corollaries of sovereignty and non-intervention - in addition to the well-recognized requirement to comply with one's treaty obligations in good Faith — should therefore give rise to a cognizable claim that economic cyber espionage violates TRIPS. On this view, the WTO agreements would not exclude a claim of economic cyber espionage simply because the conduct "involves governments obtaining information from private-sector companies located outside their territories." Arguably, it would be contrary to both the letter and spirit of the WTO agreements to fail to recognize such a claim". SKINNER, Christina Parajon. An international law response to economic cyber espionage. Connecticut Law Review, v. 46, n. 4, p. $1187-$ 1188, 2014.

32 JACKSON, John H. Sovereignty, the WTO and changing fundamentals of international law. Cambridge: Cambridge University Press, 2006. p. 165-166.

33 JACKSON, John H. Sovereignty, the WTO and changing fundamentals of international law. Cambridge: Cambridge University Press, 2006. p. 167-168.

34 SKINNER, Christina Parajon. An international law response to economic cyber espionage. Connecticut Law Review, v. 46, n. 4, p. 1198-1199, 2014.
Logo, refletindo tal consideração para o objeto deste estudo, não haveria problemas em se invocar o costume internacional ou princípios gerais de Direito Internacional para fundamentar uma decisão do Órgão de Solução de Controvérsias da OMC. A questão que se apresenta, contudo, é de natureza mais complexa: o Órgão de Solução de Controvérsias poderia extrair do costume internacional ou dos princípios gerais de Direito Internacional, além de elementos para fundamentação de suas decisões, obrigações autônomas em relação ao GATT que vinculariam os membros da OMC? Poderia uma noção imprecisa como a de "soberania econômica" - cuja existência é por si só questionável - ser fonte autônoma de obrigações para um membro e perante a qual a espionagem econômica internacional seria uma atividade contrária?

É certo que, do ponto de vista de uma teoria geral do Direito Internacional, os costumes, os tratados e os princípios gerais de Direito Internacional são fontes de direitos e obrigações em igual peso, não havendo relação de hierarquia entre as normas que impõem uns e outros. ${ }^{35}$ Todavia, a questão não é saber se um membro da OMC está vinculado a determinado princípio ou costume internacional - no caso o princípio da "soberania econômica". Trata-se, na verdade, de saber se ao Órgão de Solução de Controvérsias foi conferida, pela vontade convergente dos Membros, competência para apreciar obrigações impostas além dos acordos do GATT.

Sem que seja necessário investigar a real existência ou mesmo a extensão de um possível princípio de "soberania econômica", a resposta à indagação é negativa, isto é, o costume internacional não pode gerar obrigações autônomas para membros da OMC sem qualquer suporte em uma regra expressa do GATT. Como já afirmado anteriormente, o sistema de solução de controvérsias da OMC tem um âmbito restrito de competência, que é o de apreciar controvérsias envolvendo aplicação dos acordos que compõem o GATT 1994 e o próprio acordo constitutivo da Organização. Uma controvérsia que

35 ZEMANEK, Karl. The legal foundations of the international system: general course on public international law. Boston: Nijhoff, 1997. (Hague Academy Collected Courses, 266). p. 132; SHAW, Malcolm N. International law. 6. ed. Cambridge: Cambridge University Press, 2008. p. 123-124. Observe-se que a assertiva contrária à hierarquia foi formulada levando-se em conta apenas os tratados, os costumes e os princípios gerais de Direito Internacional. Obviamente, a questão se torna mais complexa se forem consideradas as normas jus cogens e as obrigações erga omnes. 
se fundamentasse em uma obrigação extraída de um costume internacional, sem correspondência expressa em um desses acordos, extrapolaria a competência que os membros concordaram em conferir ao Órgão de Solução de Controvérsias e, portanto, não poderia ser ali dirimida. Com efeito, uma das finalidades do sistema de solução de controvérsias é proporcionar previsibilidade e segurança às relações comerciais multilaterais $^{36}$, de sorte que a imposição de uma obrigação extraída apenas do costume internacional a um membro da OMC não satisfaria tais prudentes orientações.

\subsection{Mecanismo de apreciação de reclamações em situações de não violação (Non-violation complaints)}

Foi afirmado anteriormente que bastava que um ato estatal violasse alguma das obrigações assumidas no GATT para, em tese, ser objeto do sistema de solução de controvérsias da $\mathrm{OMC}$, o que não significa dizer que somente condutas que afrontassem diretamente tais obrigações poderiam ser ali apreciadas.

Com efeito, reconhece-se que, por mais detalhados que possam ser, os acordos que compõem o GATT eventualmente não cobrirão, por suas regras positivadas, todas as situações que se revelem prejudiciais aos compromissos comerciais. Há, de fato, lacunas no sistema, que devem ser supridas com um parâmetro genérico de reclamações entre os Membros.

Dessa forma, enquadraria-se nesta hipótese a conduta de algum membro que, mesmo sem violar diretamente umas das obrigações expressas no GATT, frustrasse um dos objetivos da Organização ou seus compromissos comerciais. ${ }^{37} \mathrm{O}$ Estado que deseja se

36 É dito no art. 3, item 2, do Anexo 2 do Acordo Constitutivo da OMC (Entendimento Relativo às Normas e Procedimentos sobre Solução de Controvérsias): "O sistema de solução de controvérsias da OMC é elemento essencial para trazer segurança e previsibilidade ao sistema multilateral de comércio. Os Membros reconhecem que esse sistema é útil para preservar direitos e obrigações dos Membros dentro dos parâmetros dos acordos abrangidos e para esclarecer as disposições vigentes dos referidos acordos em conformidade com as normas correntes de interpretação do direito internacional público. As recomendações e decisões do OSC não poderão promover o aumento ou a diminuição dos direitos e obrigações definidos nos acordos abrangidos." ORGANIZAÇÃO MUNDIAL DO COMÉRCIO. Acordo Constitutivo da Organização Mundial do Comércio, 1994. Disponível em: <http://www.mdic.gov.br/arquivo/secex/ omc/acordos/portugues/02estabeleceomc.pdf $>$. Acesso em: 9 ago. 2014. Anexo 2.

37 WORLD TRADE ORGANIZATION. Legal basis for a dispute: valer desse procedimento deve, portanto, demonstrar que suas expectativas foram frustradas pelas ações adotadas por outro Estado-Membro ou por qualquer outra situação que existir que provoque consequências de mesma natureza. ${ }^{38}$

$\mathrm{O}$ artigo XXIII do GATT define as diretrizes deste mecanismo: uma parte contratante que considere que alguma vantagem a que tem direito em decorrência do acordo, direta ou indiretamente, esteja sendo anulada ou reduzida, ou de que a realização de algum objetivo do acordo esteja sendo impedida, poderá formular representações escritas ou recomendações à outra parte contratante interessada, desde que tais efeitos sejam decorrência de: (a) do não cumprimento por outra parte contratante dos compromissos por ela assumidos em virtude do acordo; (b) da aplicação por outras partes contratante de uma medida, contrária ou não às disposições do acordo; ou (c) da existência de qualquer outra situação. ${ }^{39}$

O artigo 64.2 do acordo TRIPS sinaliza a possibilidade do aludido mecanismo ser utilizado para controvérsias, envolvendo propriedade intelectual, ainda que sua utilização estivesse sujeita a um prazo de 5 anos contados da data de entrada em vigor do Acordo Constitutivo da OMC. ${ }^{40} 41$

Seria possível, portanto, que a utilização das nonviolation complaints consista em via adequada para apreciação, na OMC, de atos que importem em obtenção clandestina de segredo de empresa.

Note-se ainda que a prática da espionagem para fins econômicos pode consistir em medida de desequilíbrio em negociações haja vista que, através da atividade,

types of complaints and required allegations in GATT, 1994. Available at: $<$ http://www.wto.org/english/tratop_e/dispu_e/disp_settlement_ cbt_e/c4s2p2_e.htm> Last access on: 02 set. 2014.

38 WORLD TRADE ORGANIZATION. Trips: non violation complaints: background and current situations, 3 december 2009. Available at: <http://www.wto.org/english/tratop_e/trips_e/ nonviolation_background_e.htm > Last access on: 02 set. 2014.

39 WORLD TRADE ORGANIZATION. General agreement on tariffs and trade. Geneva, jul. 1986. Available at: <http://www.wto. org/english/docs_e/legal_e/gatt47_e.pdf >. Last access on: 2 set. 2014. art. XXIII.

40 ORGANIZAÇÃO MUNDIAL DO COMÉRCIO. Acordo sobre aspectos dos direitos de propriedade intelectual relacionados ao comércio, 1994. Disponível em: <http://www.fd.uc.pt/CI/CEE/OI/ OMC.GATT/OMC-Anexo_1C.htm>. Acesso em: 9 ago. 2014. art. 64.2.

41 SKINNER, Christina Parajon. An international law response to economic cyber espionage. Connecticut Law Review, v. 46, n. 4, p. 1198-1199, 2014. p. 1202-1203. 
uma das partes poderia ter acesso a informações sigilosas de valor comercial, o que poderia favorecêla, indevidamente, no processo de negociação. Nessa hipótese, como não haveria, a princípio, violação direta a qualquer das obrigações assumidas no acordo TRIPS, a utilização do mecanismo das reclamações em situação de não violação seria o mais adequado.

Ainda que teoricamente possível, é preciso reconhecer algumas exigências que dificultariam a utilização das non-violation complaints para atividades de espionagem econômica cibernética. Ao apresentar uma reclamação com base nesta cláusula, o Estado-Membro deve construir uma justificativa apta a demonstrar: a) a existência de uma medida adotada por outro EstadoMembro; b) a existência de um benefício decorrente do acordo em questão; c) que a medida adotada pelo outro Estado-Membro anule o benefício de que o reclamante poderia se valer, ou seja, um nexo de causalidade entre a medida e a perda do benefício. ${ }^{42}$

Como se observa, a construção de uma justificativa aceitável para o uso da cláusula teria que superar requisitos vagos e de difícil demonstração. As poucas decisões referentes a essa cláusula sugerem que $\mathrm{O}$ "benefício" é algo referente ao acesso a mercados externos e que a "anulação" consistiria num efeito adverso e em "frustação de expectativas razoáveis", devendo-se evidenciar a relação de causalidade entre aquele e esta, não apenas provando-se uma diminuição no volume comercial. ${ }^{43}$

Por fim, mesmo diante de uma possibilidade remota de que as non-violation complaints sejam uma via adequada para dirimir problemas relacionados à espionagem econômica, a utilização do mecanismo para matéria relativa à propriedade intelectual nunca foi utilizada pelos $\mathrm{Membros}^{44}$, e está sob moratória até dezembro

42 WORLD TRADE ORGANIZATION. Legal basis for a dispute: types of complaints and required allegations in GATT, 1994. Available at: $<$ http://www.wto.org/english/tratop_e/dispu_e/disp_settlement_ cbt_e/c4s2p2_e.htm> Last access on: 02 set. 2014.

43 MATSUSHITA, Mitsuo; SCHOENBAUM, Thomas J.; MAVROIDIS, Petros C. The World Trade Organization: law, practice and police. Oxford: Oxford University Press, 2006.

44 WORLD TRADE ORGANIZATION. Trips: non violation complaints: background and current situations, 3 december 2009. Available at: <http://www.wto.org/english/tratop_e/trips_e/ nonviolation_background_e.htm> Last access on: 02 set. 2014.
2015, em virtude de decisão adotada na Conferência Ministerial em 2013. ${ }^{45}$

\section{Conclusão}

As recentes e graves revelações sobre o programa de ciberespionagem econômica chinesa aconselham avaliação de medidas que podem ser adotadas para solucionar ou ao menos mitigar o problema. Nesse contexto, o estudo crítico da proposta de uma dessas medidas, qual seja, endereçar o problema à Organização Mundial do Comércio, revelou que há sim a possibilidade de que o Órgão de Solução de Controvérsias aprecie tais atividades, dentro de balizas específicas.

Em uma avaliação puramente normativa, conclui-se que a espionagem econômica entre Estados-Membros da OMC viola o art. 39 do acordo TRIPS desde que implique em distorções concretas no comércio internacional - em atenção à finalidade do acordo sendo que a mera obtenção clandestina da informação não seria suficiente para configurar uma infração à regra.

Por outro lado, a construção de um argumento "às margens" das obrigações expressamente assumidas em um dos acordos que compõem o GATT, sustentada unicamente no costume internacional ou nos princípios gerais de direito internacional, não seria teoricamente adequada, pois os membros da OMC conferiram competência restrita ao Órgão de Solução de Controvérsias para apreciar demandas que envolvam obrigações que os vinculem apenas nos limites dos acordos do comércio internacional.

Por fim, o mecanismo de reclamações em situação de não violação (non-violation complaints) é, em tese, uma via adequada para apreciar atividades de espionagem econômica entre os membros, mas desde que sejam satisfeitos todos os requisitos impostos para o acionamento desse mecanismo - notadamente a existência de algum benefício comercial que seja anulado por outro Membro - o que na prática se revela extremamente difícil de se configurar.

45 SKINNER, Christina Parajon. An international law response to economic cyber espionage. Connecticut Law Review, v. 46, n. 4, p. 1198-1199, 2014. p. 1201-1202. 


\section{Referências}

BAKER, Christopher D. Tolerance of international espionage: a functional approach. American University International Law Review, v. 19, n. 5, p. 1091-1113, 2003.

BRASIL. Lei 9.279, de 14 de maio de 1996. Regula direitos e obrigações relativos à propriedade industrial. Disponível em: <http://www.planalto.gov.br/ ccivil_03/leis/19279.htm>. Acesso em: 9 ago. 2014.

CHABROW, Eric. The real aim of the U.S. indictment of chinese. Bank Info Security, 20 mai 2014. Available: $<$ http://www.bankinfosecurity.com/real-aim-usindictment-chinese-a-6854/op-1> Last access on: 10 aug. 2014.

DEMAREST, Geoffrey B. Espionage in international law. Denver Journal of International Law and Policy, v. 24, n. 2, p. 321-348, 1996

EXECUTIVE OFFICE OF THE PRESIDENT OF THE UNITED STATES. Administration strategy on mitigating the theft of U.S. trade secrets, feb. 2013. Available at: <http://www.whitehouse.gov/sites/default/files/ omb/IPEC/admin_strategy_on_mitigating_the_ theft_of_u.s._trade_secrets.pdf $>$ Last access on: 09 aug. 2014.

FIDLER, David. P. Economic cyber espionage and international law: controversies involving government acquisition of trade secrets through cyber technologies. American Society of International Law Insights, v. 17, n. 10, 20 mar. 2013. Available at: <http://www.asil.org/insights/ volume/17/issue/10/economic-cyber-espionage-andinternational-law-controversies-involving $>$ Last access on: 25 aug. 2014.

FIDLER, David. P. Why the WTO is not an appropriate venue for addressing economic cyber espionage. Arms Control Law, 11 feb. 2013. Available at: <http:// armscontrollaw.com/2013/02/11/why-the-wto-is-notan-appropriate-venue-for-addressing-economic-cyberespionage/> Last access on: 30 aug. 2014.

JACKSON, John H. Sovereignty, the WTO and changing fundamentals of international law. Cambridge: Cambridge University Press, 2006.

LEWIS, James A. Conflict and negotiation in cyberspace. Washington: Center for Strategic and International Studies, 2013.
LIMA, Humberto Alves de Vasconcelos. A construção do vínculo entre propriedade intelectual e comércio internacional e seus reflexos no Brasil. Revista Eletrônica Direito e Politica, v. 9, n. 2, 2014. Disponível em: $<$ http://www6.univali.br/seer/index.php/rdp/article/ view/6033>. Acesso em: 9 ago. 2014.

MANDIANT. ATP1: exposing one of China's cyber espionage Units, 2013. Available at: <http://intelreport. mandiant.com/Mandiant_APT1_Report.pdf $>$ Last access on: 09 ago. 2014.

MATSUSHITA, Mitsuo; SCHOENBAUM, Thomas J.; MAVROIDIS, Petros C. The World Trade Organization: law, practice and police. Oxford: Oxford University Press, 2006.

MCDOUGAL, Myres S.; LASSWELL, Harold D.; REISMAN, W. Michael. The intelligence function and world public order. Temple Law Quarterly, v. 46, n.3, p. 365-448, 1973.

NORTH ATALNTIC TREATY ORGANIZATION. Tallin manual on the international law applicable to cyber warfare. Cambridge: Cambridge University Press, 2013

OFFICE OF THE NATIONAL COUNTERINTELLIGENCE EXECUTIVE (ONCIX).ForeignspiesstealingUS economicsecretsincyberspace: report to Congress on foreign economic collection and industrial espionage, out. 2011. p. 1-5. Available at: $<$ http://www.ncix.gov/publications/reports/fecie_all/ Foreign_Economic_Collection_2011.pdf $>$ Last access on: 09 aug. 2014.

OPPENHEIM, Lassa. International law. 3. ed. London: Longmans, 1920.

ORGANIZAÇÃO MUNDIAL DO COMÉRCIO. Acordo Constitutivo da Organização Mundial do Comércio, 1994. Disponível em: <http://www.mdic.gov.br/arquivo/ secex/omc/acordos/portugues/02estabeleceomc.pdf $>$. Acesso em: 9 ago. 2014.

ORGANIZAÇÃO MUNDIAL DO COMÉRCIO. Acordo sobre aspectos dos direitos de propriedade intelectual relacionados ao comércio, 1994. Disponível em: <http:// www.fd.uc.pt/CI/CEE/OI/OMC.GATT/OMCAnexo_1C.htm>. Acesso em: 9 ago. 2014. 
ROBERTS, Dan; GOLDENBERG, Suzanne. USChina summit ends with accord on all but cyberespionage. The Guardian, 10 jun. 2013. Available at: <http://www.theguardian.com/world/2013/jun/09/ us-china-summit-barack-obama-xi-jinping $>$ Last access on: 10 ago. 2014.

ROGIN, Josh. NSA chief: cybercrime constitutes the greatest transfer of wealth in history. Foreign Policy, 9 jul. 2012. Available at: $<$ http://thecable.foreignpolicy.com/ posts/2012/07/09/nsa_chief_cybercrime_constitutes_ the_greatest_transfer_of_wealth_in_history> Last access on: 16 apr. 2014.

SHAW, Malcolm N. International law. 6. ed. Cambridge: Cambridge University Press, 2008.

SKINNER, Christina Parajon. An international law response to economic cyber espionage. Connecticut Law Review, v. 46, n. 4, p. 1198-1199, 2014.

STONE, Julius. Legal problems of espionage in conditions of modern conflict. In: STANGER, Roland J. (Org.) Essays on espionage and international law. Athens: Ohio University Press, 1962

SULMASY, Glenn; YOO, John. Counterintuitive: intelligence operations and international law. Michigan Journal of International Law, v. 28, p. 625-638, 2006-2007

THE UNITED STATES DEPARTMENT OF JUSTICE. U.S. charges five chinese military hackers for cyber espionage against U.S. corporations and a labor organization for commercial advantage, 19 mai 2014. Available at:<http:// www.justice.gov/opa/pr/2014/May/14-ag-528.html> Last access on: 10 aug. 2014.
UNITED STATES OF AMERICA. Economic espionage act. Washington, 2 october 1996.

WILLIAMS, Robert D. (Spy) game change: cyber networks, intelligence collection, and covert action. The George Washington Law Review, v. 79, n. 4, p. 1162-1200, 2011.

WORLD TRADE ORGANIZATION. Argentina: certain measures on the protection of patents and test data, 2002. Available: <http://www.wto.org/english/ tratop_e/dispu_e/cases_e/ds196_e.htm $>$ Last access on: 29 aug. 2014.

WORLD TRADE ORGANIZATION. General agreement on tariffs and trade. Geneva, jul. 1986. Available at: <http://www.wto.org/english/docs_e/legal_e/ gatt47_e.pdf $>$. Last access on: 2 set. 2014.

WORLD TRADE ORGANIZATION. Legal basis for a dispute: types of complaints and required allegations in GATT, 1994. Available at: <http://www.wto.org/english/ tratop_e/dispu_e/disp_settlement_cbt_e/c4s2p2_e. htm> Last access on: 02 set. 2014.

WORLD TRADE ORGANIZATION. Trips: non violation complaints: background and current situations, 3 december 2009. Available at: <http:// www.wto.org/english/tratop_e/trips_e/nonviolation_ background_e.htm> Last access on: 02 set. 2014.

ZEMANEK, Karl. The legal foundations of the international system: general course on public international law. Boston: Nijhoff, 1997. (Hague Academy Collected Courses, 266). 
Para publicar na Revista de Direito Internacional, acesse o endereço eletrônico www.rdi.uniceub.br ou www.brazilianjournal.org.

Observe as normas de publicação, para facilitar e agilizar o trabalho de edição. 